\title{
A RAIL CENTRAL DISPLACEMENT METHOD ABOUT GB-SAR
}

\author{
J. Peng a, *, J. Cai a , H. Yang a \\ ${ }^{a}$ China University of Geosciences (Beijing), 100083 Beijing, China - pengjunhuan@163.com
}

Commission VII, ThS 7

KEY WORDS: Ground Based Synthetic Aperture Radar (GB-SAR), Rail Displacement Error, Landslide Monitoring, Discontinuous GB-SAR, Artificial Corner Reflectors, Atmospheric Phase

\begin{abstract}
:
This paper presents a new method to correct rail errors of Ground Based Synthetic Aperture Radar (GB-SAR) in the discontinue mode. Generally, "light positioning" is performed to mark the GB-SAR position in the dis-continuous observation mode. Usually we assume there is no difference between the marked position and the real installation position. But in fact, it is hard to keep the GBSAR positions of two campaigns the same, so repositioning errors can't be neglected. In order to solve this problem, we propose an algorithm to correct the rail error after analyzing the GB-SAR rail error geometry. Results of the simulation experiment and the real experiment of a landslide in Lvliang, Shanxi, China, show the proposed method achieves an mm-level precision, enabling the DGBSAR mode to be used in engineering projects.
\end{abstract}

\section{INTRODUCTION}

Ground Based Synthetic Aperture Radar (GB-SAR) is a radarbased terrestrial remote sensing imaging system (Tarchi et al., 1999), consisting of a precision rail track and a radar sensor emitting and receiving microwaves repeat-pass along the rail (Noferini, 2004). It obtains the target deformation by interfering the observation data. Ku band GB-SAR is often used in deformation monitoring, as its short waves can achieve high precision. The precision of GB-SAR measurements varies from sub-millimeters to a few millimeters according to the target characteristics and the distance between sensor and target (DST). For some artificial targets, precision better than $1 \mathrm{~mm}$ is attainable (Takahashi et al., 2013). With the flexibility, GBSAR can acquire deformations from as large as several meters per hour to as small as few millimeters per year (Leva et al., 2003) by adjusting the observation model and period. So it can be applied in open pit slope stability monitoring (Casagli et al., Farina et al., 2011; Farina et al., 2012; Mecatti et Al., 2010; and Severin et al., 2011), landslides monitoring (Tarchi et al., 2003b; Luzi et al., 2006; Herrera et al., 2009; Corsini et al., 2013; Barla et al., 2010; Schulz et al., 2012), urban monitoring (Pieraccini et al., 2004; Tapete et al., 2013; Pipia et al., 2013), structure monitoring (Tarchi et al., 1997), dam monitoring (Tarchi et al.,1999; Alba et al., 2008; Luzi et al., 2010a), and glacier monitoring (Luzi et al., 2007, Noferini et al., 2009; Hyangsun and Hoonyol, 2011).

GB-SAR data can be acquired using two types modes: the continuous (C-GBSAR) and the dis-continuous (D-GBSAR). For the C-GBSAR mode, instruments are installed in situ, acquiring data on a regular base (e.g., every a few minutes). For the D-GBSAR mode, instruments are installed in each campaign and revisited a given site periodically (e.g., weekly, monthly or yearly) depending on the deformation speed (Noferini et al., 2008; Luzi et al., 2010b). D-GBSAR is especially useful in monitoring slow deformations.
Traditional GB-SAR algorithm assumes that interferometric images are constituted by deformation phase, topographic phase, atmospheric phase and noise. However, in the D-GBSAR mode, it is hard to ensure the GB-SAR positions to exactly the same in two campaigns, so this repositioning error called GB-SAR rail error in this paper should be considered. In this case, "light positioning" is usually used to reduce the GB-SAR rail error, i.e., by simply materializing the GB-SAR location using some marks. Then co-registrations should be implemented. Detailed information of the algorithms can be found in Lin et al. (1992) and Hanssen (2011). However, as the GB-SAR precision can reach the submillimeter level, the co-registration error and residual error of rail still have impact on the measurement results even after marking and co-registration. In order to acquire reliable deformation results, we need correct the GBSAR rail error.

To estimate and eventually reduce the GB-SAR rail error, a novel technique is proposed discussed in this paper. The first part of this paper introduces fundamentals and principles of GB-SAR, and then a new error model is proposed. Orbit deformation is simulated by computer, and the effect of each component to the monitoring result is analyzed. The last part presents a successful application example of D-GBSAR in monitoring the deformation of a landslide in Lvliang, Shanxi, China, using artificial corner reflectors.

\section{MATERIALS AND METHODS}

\subsection{GB-SAR Error source analysis}

GB-SAR uses interferometric techniques to derive the deformation and topography of the observation area. Traditional GB-SAR algorithm assumes that interferometric images are constituted by deformation phase, topographic phase, atmospheric phase and noise (O. Monserrat et al., 2014). Deformation phase is regarded to the target displacement; topographic phase describes the elevation information; 
atmospheric phase is related to atmospheric parameters which could be corrected by many different approaches (Noferini et al., 2008; Iglesias et al., 2013; Iannini and Guarnieri, 2011); noise phase can be reduced by filtering. So the mode can be expressed as:

$$
\Delta \phi=-\frac{4 \pi}{\lambda} \Delta R+\Delta \phi_{\text {atm }}+\Delta \phi_{\text {noise }}
$$

where

$$
\begin{aligned}
& \Delta \phi=\text { differential interferogram phase } \\
& \Delta R=\text { DST } \\
& \Delta \phi_{\text {atm }}=\text { differential atmospheric phase } \\
& \Delta \phi_{\text {noise }}=\text { differential noise phase }
\end{aligned}
$$

Atmospheric phase is compensated by the method proposed in (Tarchi et al. 1999) which is adapted to the ground-based geometry.Delaying phase due to the weather conditions along a path of length $\mathrm{R}$ is :

$$
d e f_{a t m}=\left(7.76 \times 10^{-5} \frac{P(\text { mbar })}{T(K)}+3.73 \times 10^{-1} \frac{e(m b a r)}{T(K)^{2}}\right) \cdot R^{(2)}
$$

where $\quad P=$ air pressure in millibars

$\mathrm{T}=$ temperature in kelvin

$\mathrm{e}=$ partial pressure of the water vapor in millibars

As the GB-SAR rail positions in two campaigns can't be identical, the GB-SAR rail error, called baseline in spaceborne SAR, is introduced. GB-SAR rail errors cause low coherence and instable displacement between two images, which can't be corrected by spaceborne SAR methods directly due to different geometry between spaceborne SAR and GB-SAR. Based on this, we analyses the geometric relationship between radar sensors and targets, and propose a correction algorithm. The GB-SAR rail error is decomposed to three components in the range, azimuth and vertical direction, respectively. Figure 1(a, c, d) show the geometrical relationship of the three directions. Obviously, the range and azimuth components are related to the azimuth angle and the DST. The error of vertical component correlates to the vertical displacement, and the range and elevation of the target. So the three components could be expressed as:

$$
\begin{aligned}
\Delta \phi_{r, a} & =-\frac{4 \pi}{\lambda} \varepsilon_{1} \sin \theta \\
\Delta \phi_{r, \mathrm{r}} & =-\frac{4 \pi}{\lambda} \varepsilon_{2} \cos \theta \\
\Delta \varphi_{r, v} & =-\frac{4 \pi}{\lambda} \varepsilon_{3} \frac{h}{R}
\end{aligned}
$$

where $\lambda=$ wave length

$\Delta \phi_{r, a}=$ azimuth direction error phase

$\Delta \varphi_{r, r}=$ range direction error phase

$\Delta \varphi_{r, v}=$ vertical direction error phase

$\varepsilon_{1}, \varepsilon_{2}$ and $\varepsilon_{2}=$ rail displacement projected on to the azimuth, the range and the vertical direction

$$
\begin{aligned}
& \theta=\text { azimuth angle } \\
& \mathrm{h}=\text { elevation between radar and target }
\end{aligned}
$$

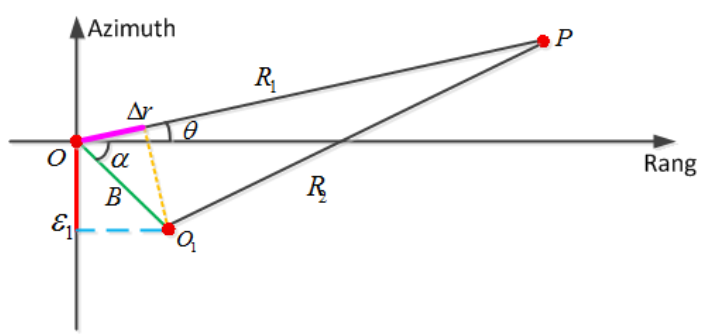

(a)

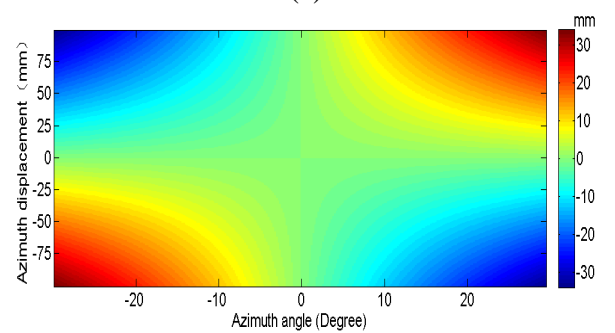

(b)

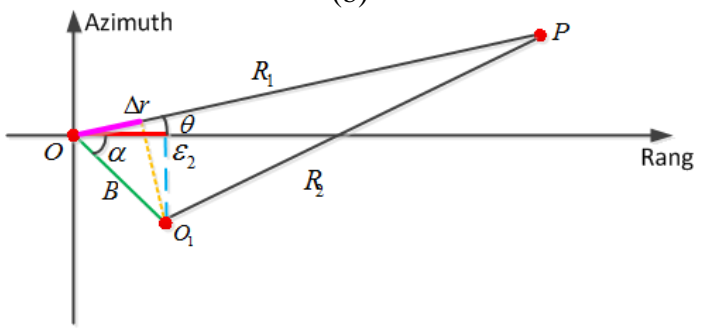

(c)

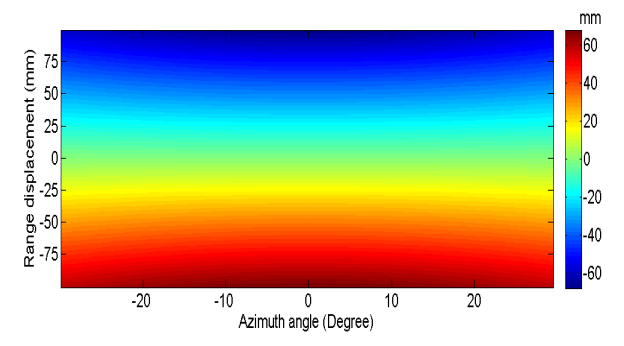

(d)

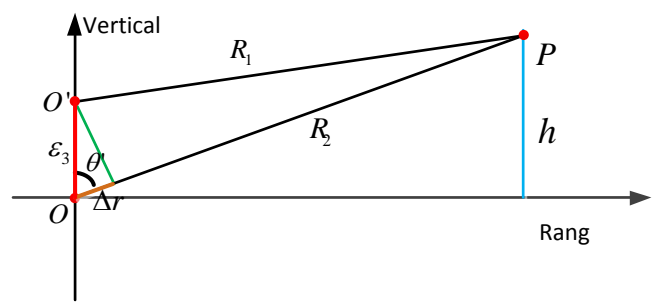

(e)

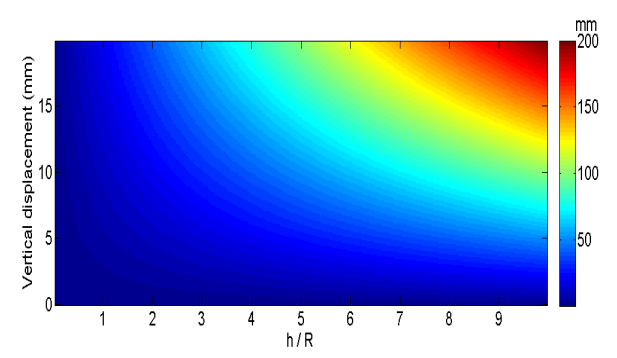

(f) 
Figure 1. Geometrical relationship of the three directions and simulated results. (a), (b) Azimuth direction. (c), (d) Range direction. (e), (f) Vertical direction.

As Figure 1(b, d, f) show the influence of range, azimuth and vertical direction rail error on the displacement. Among them, the error of the azimuth is related to rail displacement and azimuth angle, see Fig.1b. With an azimuth angle of $20^{\circ}$, the displacement is $2.92 \mathrm{~mm}$, and the GB-SAR rail error will be $1 \mathrm{~mm}$. Figure 1(d) shows the error of the range is also correlated to rail displacement and azimuth angle. When the angle of azimuth is $20^{\circ}$ and the range displacement is $1.06 \mathrm{~mm}$, the rail error will up to $1 \mathrm{~mm}$. Figure 1(c) shows correlation between the rail error in the vertical direction with the displacement, range and elevation of the target. If the range between target and radar sensor is $200 \mathrm{~m}$, elevation is $50 \mathrm{~m}$, and the displacement of vertical is $4 \mathrm{~mm}$, the rail error is $1 \mathrm{~mm}$. Compared with the azimuth direction rail error, the range component has greater effect on the result.

In addition, a small displacement in the azimuth direction has great impact on the result precision, so the result will be unreliable if the GB-SAR rail error is not corrected.

In practice, errors of the three directions (the range direction, azimuth direction and vertical) should be compensated together. A compound function is expressed as:

$$
\begin{aligned}
& \phi_{\text {rail }}=-\frac{4 \pi}{\lambda} B \cos (\theta+\alpha) \\
& =-\frac{4 \pi}{\lambda}\left(\varepsilon_{1} \cos \theta-\varepsilon_{2} \sin \theta+B \frac{h}{R}\right)
\end{aligned}
$$

where $\quad B=$ the length of base line

$\mathrm{T}=$ temperature in kelvin

$\mathrm{e}=$ partial pressure of the water vapor in millibars

So the interferogram can be written as:

$$
\begin{aligned}
& \Delta \varphi=-\frac{4 \pi}{\lambda}\left(R_{2}-R_{1}\right)+\left(\phi_{\text {atm } 2}-\phi_{\text {atm } 1}\right) \\
& +\left(\phi_{\text {rail2 }}-\phi_{\text {rail1 }}\right)+\left(\phi_{\text {noise } 2}-\phi_{\text {noise } 1}\right)
\end{aligned}
$$

The EQ.7 can be taken as a linear system with 6 unknowns. Taking $\mathrm{N}$ stationary points $(\mathrm{N}>6)$ into consideration, the equation can be solved in a least square sense.

\subsection{Simulate rail error and atmospheric phase compensation respectively}

To verify the error correction model, a simulated experiment with only GB-SAR rail error is designed. GB-SAR instruments are installed in proper sites. Then we move the GB-SAR rail few minutes later to simulate the GB-SAR rail error. At the same time, real displacement of GB-SAR rail is recorded. In order to detect the GB-SAR rail error, we need eliminate the deformation phase, atmospheric phase and noise. Deformation phase is assumed to be zero in this experiment. The atmospheric phase is compensated by the empirical algorithm. And the noise is reduced by filtering. Then only the GB-SAR rail error left. Figure 2 and 3 show the original interferogram and the one after compensated.

Specifically, we firstly move the GB-SAR system $10 \mathrm{~mm}$ and then $70 \mathrm{~mm}$ along the azimuth direction .Their interferogram is showed in Figure 2 (a) and (c). Obviously, the interferometric fringes are parallel to the azimuth direction, and they increase with the increase of displacements. These interferogram fringes are caused by the displacement of GB-SAR rail. Because other influential components values are relatively small, the effect of rail displacement is obvious. As the compensated results show, see Figure 2 (b) and (d), the computing rail errors are $8 \mathrm{~mm}$ and $73 \mathrm{~mm}$ which have differences of $2 \mathrm{~mm}$ and $3 \mathrm{~mm}$ with the real value.

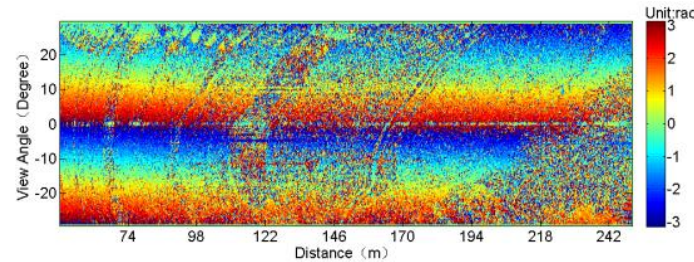

(a)

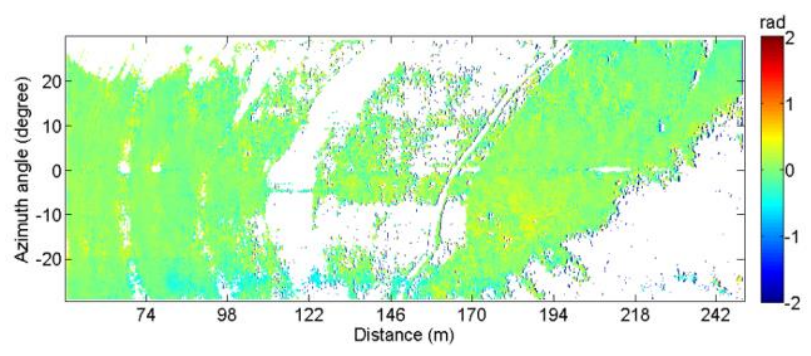

(b)

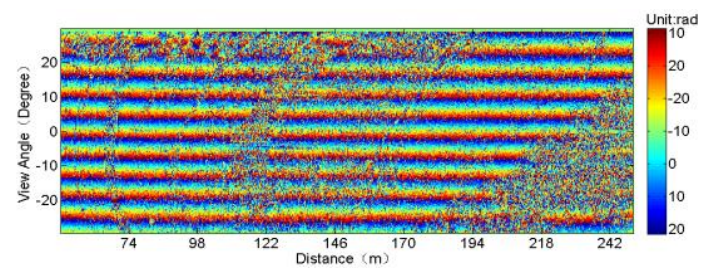

(c)

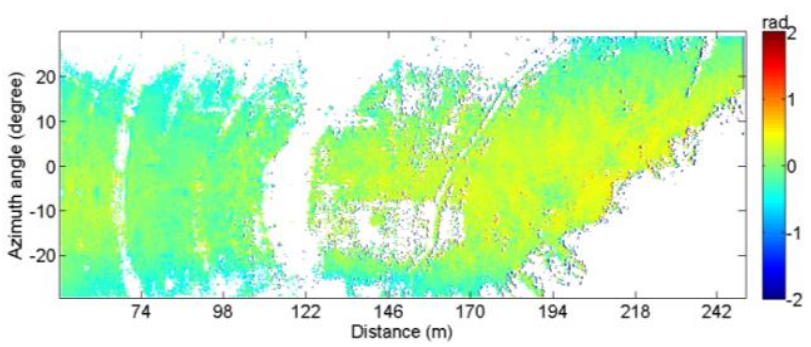

(d)

Figure 2. Rail error in the azimuth direction. (a) Interferogram containing $10 \mathrm{~mm}$ rail error in the azimuth direction. (b) $10 \mathrm{~mm}$ rail error competition result. (c) Interferogram containing $70 \mathrm{~mm}$ rail error in the azimuth direction. (d) $70 \mathrm{~mm}$ rail error compensation result.

Secondly, move the GB-SAR system $20 \mathrm{~mm}$ and then $80 \mathrm{~mm}$ along the range direction. Their interferogram is showed in Figure 3 (a) and (c), which contain marked interferometric fringes. And the interferometric fringes are parallel neither to the range direction nor the azimuth direction, but have a circlelike shape. As the compensated results show, see Figure 3 (b) and (d), the computed rail error is $16 \mathrm{~mm}$ and $79 \mathrm{~mm}$, which have differences of $4 \mathrm{~mm}$ and $6 \mathrm{~mm}$ with the real value. 


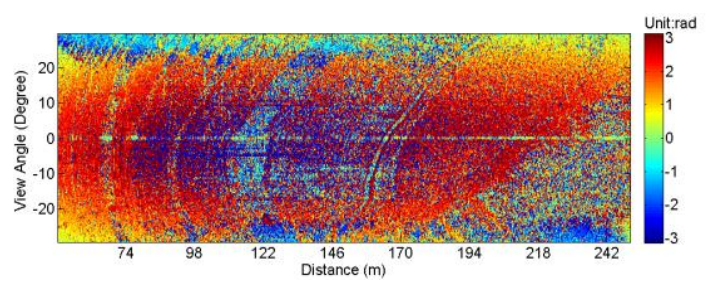

(a)

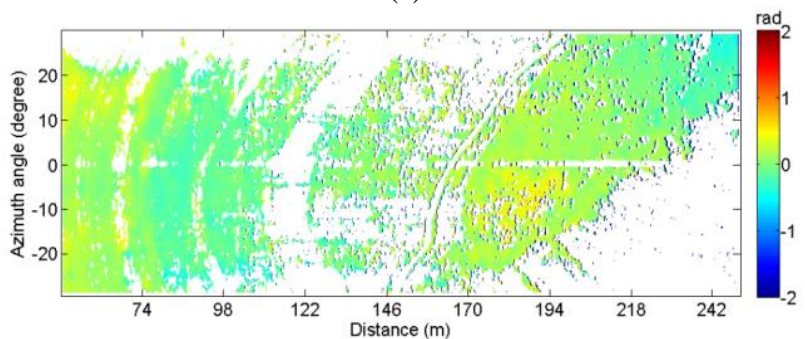

(b)

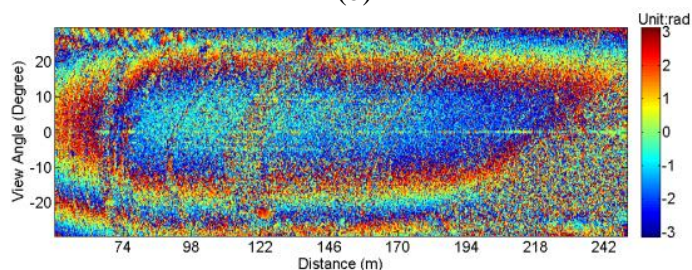

(c)

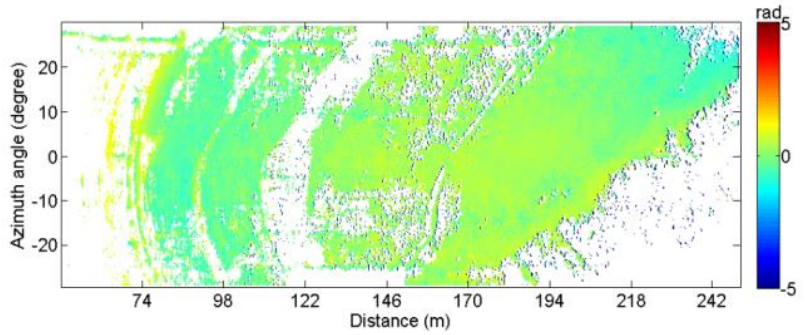

(d)

Figure 3. Rail error in the range detection. (a) Interferogram containing $20 \mathrm{~mm}$ rail error in the range direction. (b) $20 \mathrm{~mm}$ rail error competition result. (c) Interferogram containing $85 \mathrm{~mm}$ rail error in the range direction. (d) $70 \mathrm{~mm}$ rail error compensate result.

The simulation experiment demonstrates that the proposed method is reasonable and flexible to correct the GB-SAR rail error, providing an mm-level correction precision. The precision in the azimuth direction is better than that in the range direction, because the latter shares similar spatial distribution characteristics with the atmospheric phase (both of them are related to DST), making difficult to distinguish them from each other. Also, the big the distance is, the more difficult the compensation of rail errors in both directions will be.

\section{APPLICATION}

We applied the proposed method to estimate the deformation of a landslide occurred in Lingjiaping railway station located in Lvliang County, Shanxi, China. The exact position of the landside is at the right side of the MD II K53+370 +680 line in the station. In the middle of November, 2013, a cutting evacuation project was started around the MD II K53+50 +630 line. On December 14, 2013, two ring-like cracks appeared on the right side of the through cut, then a landslide happened on December 18. The landslide region is located on the west bank of the Qiushui River, in the middle of the slope between the Qiushui River and loess hill. The gradient of bedrock surface ranges between $0 \sim 24^{\circ}$. The excavation area centered on the terrace and the leading edge. The through cut slope has crossed the earth-rock interface. Figure 4 is a picture of the experiment area. The slop has been reinforced in 2015, but is not stable, so it is suitable to be an experiment area. Twelve corner reflectors installed on the landslide with concrete can be used as stable points to estimate the GB-SAR error phase.

The GB-SAR system used in the experiment is developed by China University of Geosciences (Beijing) and the Beijing Institute of Technology. Figure 5 shows the SDMR-1 GB-SAR system, which consists of a continuous-wave step-frequency transceiver unit working at Ku-band. The band width of the system is $500 \mathrm{MHz}$, and the sample interval is $2 \mathrm{~min}$. The range resolution and the azimuth resolution is $0.3 \mathrm{~m}$ and $4.5 @ 1 \mathrm{Km}$, respectively. Detailed information of the system is showed in Table 1.

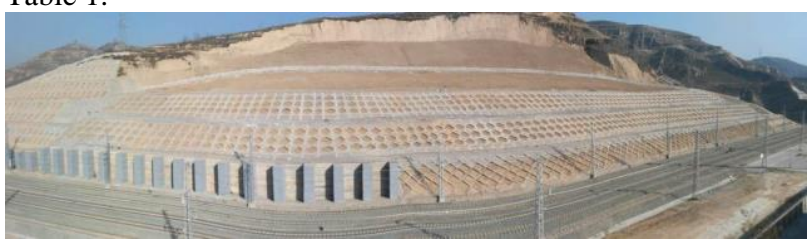

Figure 4. Experiment area

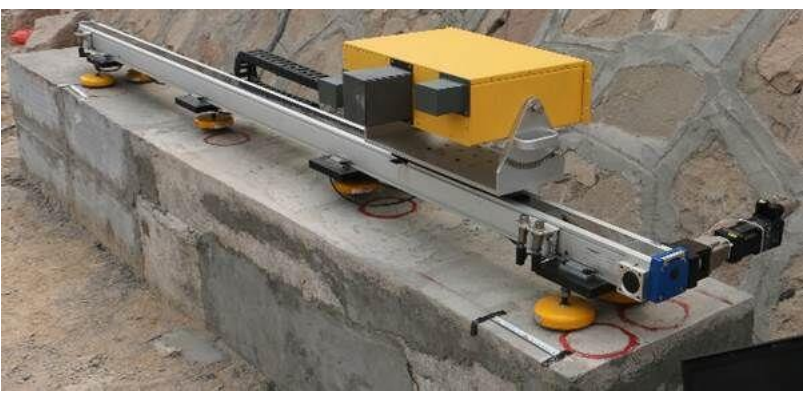

Figure 5. GB-SAR system used in the experiment

\begin{tabular}{|l|c|}
\hline Name & Value \\
\hline Central Frequency & $16.02 \mathrm{GHz}$ \\
Linear Scanning Length & $2.4 \mathrm{~m}$ \\
Range Resolution & $0.3 \mathrm{~m}$ \\
Bandwidth & $500 \mathrm{MHz}$ \\
Illuminating Distance & $30 \mathrm{~m}-3000 \mathrm{~m}$ \\
Azimuth Resolution & $4.5 \mathrm{~m} @ 1 \mathrm{Km}$ \\
\hline
\end{tabular}

Table 1. Information of the SDMR-1 GB-SAR system

\begin{tabular}{|l|c|}
\hline Name & Precision \\
\hline Temperature & $0.2^{\circ} \mathrm{C}$ \\
Humidity & $0.3 \% \mathrm{RH}$ \\
Air pressure & $0.5 \mathrm{hPa}$ \\
Elevation & $5 \mathrm{~m}$ \\
\hline
\end{tabular}

Table 2. Parameters of Portable Meteorograph

Atmospheric phase is related to the DST, so it could be expressed as:

$$
\varphi_{\text {atm }}=-\frac{4 \pi}{\lambda}\left(a_{0}+a_{1} R+a_{2} R^{2}\right)
$$

where $\quad a_{0}, a_{1}, a_{2}=$ multinomial coefficient 
Meteorological parameters (e.g., temperature, humidity, and air pressure), elevation, latitude and longitude are obtained by the TYD-SCW1 Portable Meteorograph. Precision of this instrument is listed in Table 2. Figure 6 (c) and (d) show the correction results of atmospheric phase by Quadratic model and Empirical model, respectively. These similar results show that the two algorithms are both effective to correct the atmospheric phase.

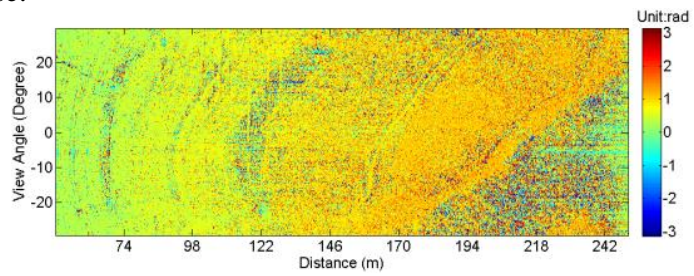

(a)

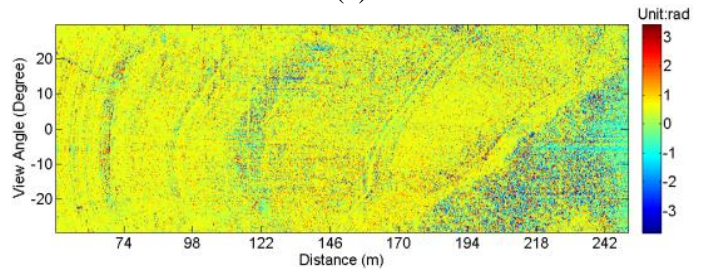

(b)

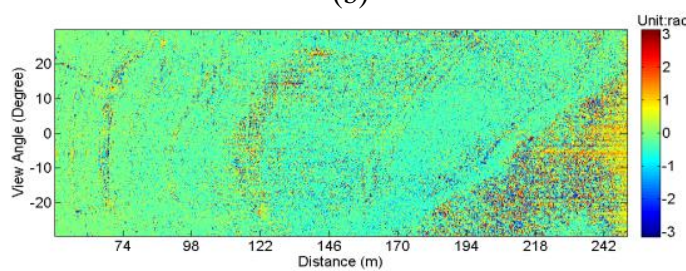

(c)

Figure 6. Comparison of empirical models. (a) Original interferogram. (b) Quadratic model compensation result. (c)

Empirical model compensation result.

Twelve corner reflectors were installed on the slide slop, and the GB-SAR was put facing the landslide, so all corner reflectors could be detected in one scan. Two D-GBSAR observation campaigns were performed (10/07/2015, $30 / 05 / 2015)$ with an interval of 41 days. "Light positioning" was used in the first campaign, so the marks can guide the instrument installation in the second campaign. But it is impossible to ensure exactly same installation positions in two campaigns, so correcting the GB-SAR rail error after interfering the two campaign images is necessary. Chose one image from each campaign for interfering, and the interferogram is showed in Figure 7(a). Clearly, both the GB-SAR rail error and atmospheric phase are related to the DST. Then the GB-SAR rail error can be estimated by the proposed algorithm. Displacement in the range direction and azimuth direction are $5.0 \mathrm{~mm}$ and $2.9 \mathrm{~mm}$, respectively. Figure 7 (b) shows the sum of rail determination error and atmospheric phase. Final result of the deformation phase is shown in Figure 7(c), where deformation area is marked in yellow, with a sub-mm-level precision.

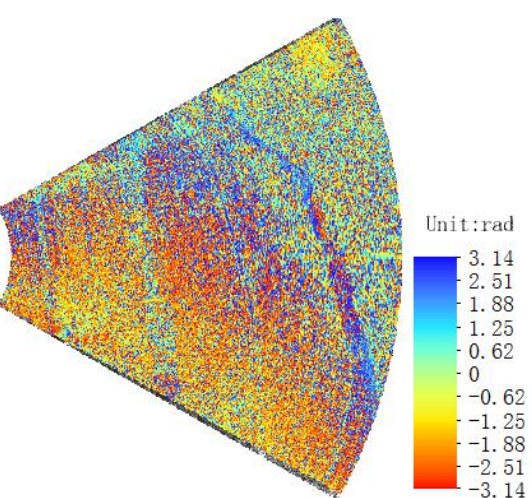

(a)

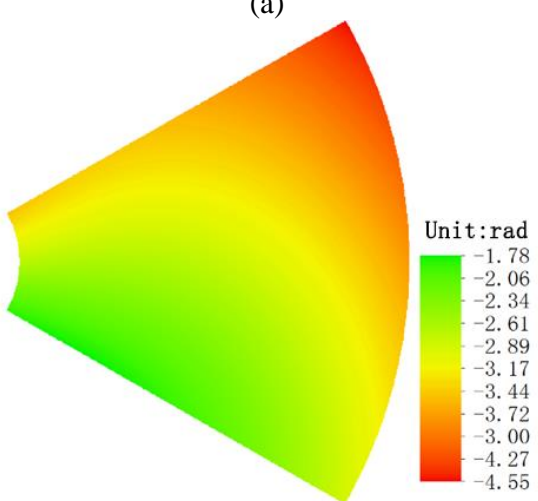

(b)

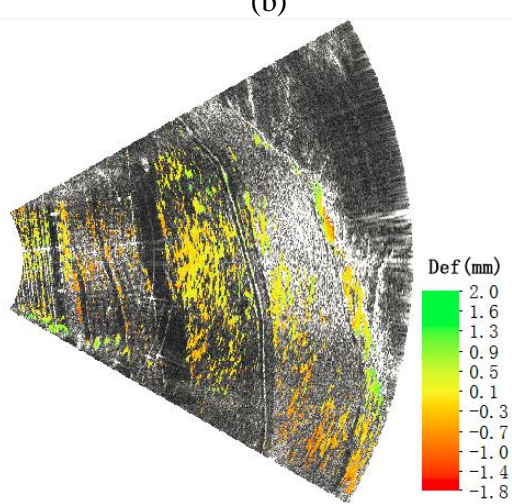

(c)

Figure 7. Experiment data. (a) Original Interferogram phase. (b) Corrected phase. (c) Deformation.

\section{CONCLUSIONS}

This paper presents a new method to correct GBSAR rail errors in a discontinue mode. Compared with C-GBSAR, D-GBSAR is preferred for its lower monitoring cost, as the same instrument can be used in different monitoring several sites. But it also introduces new errors called GBSAR rail error, which generally can be reduced by "light positioning" (i.e., by simply materializing the GBSAR location using some marks). However, as the GB-SAR can achieve submillimeter precision, the coregistration error and the residual rail error of still affect the measurement results, even after "light positioning" and coregistration. Focusing on the geometry between GBSAR sensor and target, this paper deduced the formula of rail errors in the range, azimuth and vertical directions. When applied to simulation and real experiment, the new method achieved precisions up to mm-level, indicating it is quite applicable to compensate for GBSAR rail errors. The new algorithm can also 
be applied to urban monitoring, structure monitoring and open pit mine monitoring.

\section{ACKNOWLEDGMENTS}

This work was supported by the following research projects: the National Natural Science Foundation of China (41304012, 61427802, 41330634, 41374016); the Fundamental Research Funds for the Central Universities (2652015180). Hunan Province Key Laboratory of Coal Resources Clean-utilization and Mine Environment Protection (E21422). The authors would like to thank anonymous reviewers who gave valuable suggestion that has helped to improve the quality of the manuscript.

\section{REFERENCES}

Alba, M., Bernardini, G., Giussani, A., Ricci, P.P., Roncoronia, F., Scaioni, M., Valgoic, P., Zhangd, K., 2008. Measurement of dam deformations by terrestrial interferometric techniques. Int. Arch. Photogramm., Remote Sens. Spatial Inf. Sci. 37 (part b1), 133-139.

Barla, G., Antolini, F., Barla, M., Mensi, E., Piovano, G., 2010. Monitoring of the Beauregard landslide (Aosta Valley, Italy) using advanced and conventional techniques. Eng. Geol. 116 (3), 218-235.

Casagli, N., Catani, F., Del Ventisette, C., Luzi, G., 2010. Monitoring, prediction, and early warning using ground-based radar interferometry. Landslides 7 (3), 291-301.

Corsini, A., Berti, M., Monni, A., Pizziolo, M., Bonacini, F., Cervi, F., Truffelli, G., 2013. Rapid assessment of landslide activity in Emilia Romagna using GB-InSAR short surveys. In: Landslide Science and Practice. Springer, Berlin, pp. 391-399.

Farina, P., Leoni, L., Babboni, F., Coppi, F., Mayer, L., Ricci, P., 2011. IBIS-M, an innovative radar for monitoring slopes in open-pit mines. In: Proc., Slope Stability 2011: International Symposium on Rock Slope Stability in Open Pit Mining and Civil Engineering, Vancouver (Canada), 18-21September.

Farina, P., Leoni, L., Babboni, F., Coppi, F., Mayer, L., Coli, N., Thompson, C., 2012. Monitoring engineered and natural slopes by ground-based radar: methodology, data processing and case studies review. In: Proc. SHIRMS 2012: Southern Hemisphere International Rock Mechanics Symposium, Sun City (South Africa), 15-17 May.

Ferretti, A., Prati, C., Rocca, F., (2001), Permanent scatterers in SAR interferometry. IEEE Trans. Geosci. Remote Sens. 39 (1), 8-20.

Fortuny-Guasch, J. (2009), A fast and accurate far-field pseudopolar format radar imaging algorithm. IEEE Trans. Geosci. Remote Sens. 47 (4), 1187-1196.

Hanssen, R., 2001. Radar interferometry. Ed. Kluwer Academic Publishers, Dordrecht (The Netherlands).

Herrera, G., Fernandez-Merodo, J.A., Mulas, J., Pastor, M., Luzi, G., Monserrat, O., 2009. A landslide forecasting model using ground based SAR data: the Portalet case study. Eng. Geol. 105 (3-4), 220-230.
$\mathrm{Hu}$ Cheng, Zhu Mao, Zeng Tao, Tian Weiming, Mao Cong(2015), High-precision Deformation Monitoring Algorithm for GB-SAR System: Rail Determination Phase Error Compensation. SCIENCE CHINA Information Sciences, doi: 10.1007/s11432-015-5446-z.

Hyangsun, H., Hoonyol, L., (2011), Motion of Campbell glacier, east Antarctica observed by satellite and ground-based interferometric synthetic aperture radar. IEEE. In Proceedings of the 3rd Internation Asia-Pacific Conference on Synthetic Aperture Radr.

Iannini, L., Guarnieri, A.M., 2011. Atmospheric phase screen in ground-based radar: statistics and compensation. IEEE Geosci. Remote Sens. Lett. 8 (3), 537-541.

Iglesias, R., Fabregas, X., Aguasca, A., Mallorqui, J.J., LopezMartinez, C., Gili, J.A., Corominas, J., 2013. Atmospheric phase screen compensation in ground-based SAR with a multiple-regression model over mountainous regions. IEEE Trans. Geosci. Remote Sens. 99, 1-14.

Leva, D., Nico, G., Tarchi, D., Fortuny, J., Sieber, A.J., 2003, Temporal analysis of a landslide by means of a ground-based SAR interferometer. IEEE Trans. Geosci. Remote Sens. 41, 745 $-752$.

Lin, Q., Vesecky, J.F., Zebker, H.A., 1992. New approaches in interferometric SAR data processing. IEEE Trans. Geosci. Remote Sens. 30, 560-567.

Luzi, G., Pieraccini, M., Mecatti, D., Noferini, L., Macaluso, G., Galgaro, A., Atzeni, C., 2006. Advances in ground based microwave interferometry for landslide survey: a case study. Int. J. Remote Sens. 27 (12), 2331-2350.

Luzi, G., Pieraccini, M., Mecatti, D., Noferini, L., Macaluso, G., Tamburini, A., Atzeni, C., 2007. Monitoring of an alpine glacier by means of ground-based SAR interferometry. IEEE Geosci. Remote Sens. Lett. 4 (3), 495-499.

Luzi, G., Crosetto, M., Monserrat, O., 2010a. Advanced Techniques for Dam Monitoring. In: Proc. II International Congress on Dam Maintenance and Rehabilitation, Zaragoza, Spain, 23-25 November.

Luzi, G., Monserrat, O., Crosetto, M., Copons, R., Altimir, J., 2010b. Ground-based SAR interferometry applied to landslide monitoring in mountainous areas. In: Proc. Mountain Risks Conference, Florence, Italy, 24-26 November.

Massonnet, D., Rossi, M., Carmona, C., et al. (1993), The displacement _eld of the landers earthquake mapped by radar interferometry. Nature. 364: 138-142.

Massonnet, D., Arnaud, A., (1995), Deation of Mount Etna monitored by space radar interferometry. Nature. 375:567-570.

Mecatti, D., Macaluso, G., Barucci, A., Noferini, L., Pieraccini, M., Atzeni, C., 2010. Monitoring open-pit quarries by interferometric radar for safety purposes. In: Proc. European Radar Conference (EuRAD), Paris, France, 30 September-1 October, pp. 37-40.

Monserrat, O., Crosetto, M., and Luzi, G. (2014), A review of ground-based SAR interferometry for deformation 
measurement. ISPRS Journal of Photogrammetry and Remote Sensing. 93, 40-48.

Nicola Casagli, Filippo Catani, Chiara Del Ventisette, Luzi Guido (2010), Monitoring, prediction, and early warning using ground-based radar interferometry, Landslides, 7 (3), 291 - 301

Nico, G., Leva, D., Fortuny-Guasch, J., Antonello, G., Tarchi, D. (2005). Generation of digital terrain models with a groundbased SAR system. IEEE Trans. Geosci. Remote Sens. 43 (1), 45-49.

Noferini, L., 2004. Processing techniques of microwave data acquired by continuous wave stepped frequency radar. $\mathrm{PhD}$ thesis, Università degli Studi di Firenze.

Noferini, L., Takayama, T., Mecatti, D., Macaluso, G., Luzi, G., Atzeni, C., 2008. Analysis of Ground-Based SAR data with diverse temporal baselines. IEEE TGRS 46 (6), 1614-1623.

Noferini, L., Mecatti, D., Macaluso, G., Pieraccini, M., Atzeni, C., 2009. Monitoring of belvedere glacier using a wide angle GB-SAR interferometer. J. Appl. Geophys. 68 (2), 289-293.

Pieraccini, M., Luzi, G., Mecatti, D., Fratini, M., Noferini, L., Carissimi, L., Franchioni, G., Atzeni, C., 2004. Remote sensing of building structural displacements using a microwave interferometer with imaging capability. Non Destruct. Test. Eval. 37(7), 545-550.

Pipia, L., Fabregas, X., Aguasca, A., Lopez-Martinez, C., 2013. Polarimetric temporal analysis of urban environments with a ground-based SAR. IEEE Trans. Geosci. Remote Sens. 51 (4), 2343-2360.

Schulz, W.H., Coe, J.A., Shurtleff, B.L., Panosky, J., Farina, P., Ricci, P.P., Barsacchi, G., 2012. Kinematics of the Slumgullion landslide revealed by ground-based InSAR surveys. In: Proc. Landslides and Engineered Slopes: Protecting Society through Improved Understanding - the 11th International and 2nd North American Symposium on Landslides and Engineered Slopes, Banff (Canada), 3-8 June, pp. 1273-1279.

Severin, J., Eberhardt, E., Leoni, L., Fortin, S., 2011. Use of ground-based synthetic aperture radar to investigate complex 3D pit slope kinematics. In: Proc. Slope Stability 2011: International Symposium on Rock Slope Stability in Open Pit Mining and Civil Engineering, Vancouver, Canada, 18-21 September.

Takahashi, K., Matsumoto, M., Sato, M. 2013. Continuous observation of natural-disaster-affected areas using groundbased SAR interferometry. IEEE J. Sel. Top. Appl. Earth Observations Remote Sens. 6 (3), 1286 - 1294.

Tapete, D., Casagli, N., Luzi, G., Fanti, R., Gigli, G., Leva, D., 2013. Integrating radar and laser-based remote sensing techniques for monitoring structural deformation of archaeological monuments. J. Archaeol. Sci. 40 (1), 176-189.

Tarchi, D., Ohlmer, E., Sieber, A.J., 1997. Monitoring of structural changes by radar interferometry. J. Res. Nondestruct. Eval. 9(4), 213-225.

Tarchi, D., Rudolf, H., Luzi, G., Chiarantini, L., Coppo, P., Sieber, A.J. (1999). SAR interferometry for structural changes detection: a demonstration test on a dam. In: Proc. IGARSS 1999, Hamburg, Germany, pp. $1522-1524$.

Tarchi, D., Casagli, N., Moretti, S., Leva, D., Sieber, A.J., 2003. Monitoring landslide displacements by using ground-based radar interferometry: application to the Ruinon landslide in the Italian alps. J. Geophys. Res. 108 (10), 1-14. 